\title{
XVIII. On the amount of the elevations attributable to compression through the contraction during cooling of a solid earth
}

Rev. O. Fisher M.A. F.G.S.

To cite this article: Rev. O. Fisher M.A. F.G.S. (1887) XVIII. On the amount of the elevations attributable to compression through the contraction during cooling of a solid earth, Philosophical Magazine Series 5, 23:141, 145-149, DOI: 10.1080/14786448708627991

To link to this article: http://dx.doi.org/10.1080/14786448708627991

曲 Published online: 29 Apr 2009.

Submit your article to this journal $[\pi$

Џll Article views: 5

Q View related articles $\sqsubset$ 
where the right-hand side depends on the collisions between the two kinds of gas in the layer, $s$ being the semi-sum of the diameters. From these we obtain

$\frac{d \mathrm{G}_{1}}{d t}=\left(\frac{3}{16 s^{2}} \frac{\mathrm{P}_{1}+\mathrm{P}_{2}}{\sqrt{\pi h_{1} h_{2}\left(h_{1}+h_{2}\right)}} \cdot \frac{1}{p}+\frac{1}{3 n}\left(n_{21} \mathfrak{\complement}_{1}+n_{12} \mathfrak{\complement}_{1}\right)\right) \frac{d^{2} \mathrm{G}_{1}}{d x^{2}}$.

In the special case, when the masses and diameters are equal in the two gases, the diffusion-coefficient (the multiplier of $\frac{d^{2} \mathrm{G}_{1}}{d x^{2}}$ above) has the value

$$
\left(\frac{3}{4} \sqrt{\frac{\pi}{2}}+\frac{1}{3} \mathrm{C}_{1}\right) \frac{\lambda}{0 \cdot 677 \sqrt{ } h}=\frac{\lambda}{\sqrt{ } h} 1.785 .
$$

It is therefore inversely as the density, and directly as the square root of the absolute temperature. And in the case of two infinite vessels, connected by a tube of length $l$ and section $\mathrm{S}$, and containing two gases whose particles have equal masses and diameters, the rate of flow of either is $\frac{\mathrm{S} \rho \lambda}{l \sqrt{ } h} 1 \cdot 785$ in mass per unit of time.

Other cases are treated; and among these it is shown that with equal masses, and constant semi-sum of diameters, difference of diameters favours diffusion.

XVIII. On the Amount of the Elevations attributable to Compression through the Contraction during Cooling of a Solid Earth. By Rev. O. Fisher, M.A., F.G.S.*

T $\mathrm{T}$ is now thirteen years since I first published in the 'Transactions of the Cambridge Philosophical Society' $†$, and, at a later date, in my 'Physics of the Earth's Crust' $\$$, an attempt to estimate the mean height of the elevations which compression, resulting from the contraction due to cooling, might give rise to upon the earth considered as a solid globe.

A remark from my friend Mr. Davison, who is working on this subject, has suggested to me that the investigation I have given is not quite satisfactory; and I now offer the following as an improvement.

If we are to attribute the corrugations which we meet with in the earth's crust to compression arising from the secular cooling of a solid globe, we must assume, as I have tacitly

* Communicated by the Author.

$\dagger$ Vol. xii. pt. 2. Read Dec. 1, 1873 .

f Macmillan's, 1881. 
done in my former work, that the matter in each layer retains its horizontal extension during the settlement into its present position. On this supposition the corrugations will clearly be influenced by the sphericity of the surface. But if we make use of Sir W. Thomson's expression* for the temperature at any depth, wo must recollect that he neglects the sphericity. Still it seems probable that his law of cooling for an infinite plain will be sufficiently applicable to the globe to make the following of some value. For it is evident that the temperaturecurve for the sphere will be of a similar character, though not exactly of a similar form ; the more rapid escape of heat towards the convex surface causing the ordinates to decrease somewhat more rapidly as the free surface of the sphere is approached.

Let a layer of the globe at a distance $z^{\prime}$ descend, by cooling of the matter beneath it, to the distance $z$ from the centre $C$. Then our assumption, that this layer retains its horizontal extension, necessitates that we suppose the voluminal contraction to take place wholly in the vertical dimension.

Let $\mathrm{E}$ be the coefficient of voluminal contraction. If, then, the layer in question has fallen through $\theta^{\circ}$ since it solidified, we must have

or

$$
\begin{aligned}
& d z=(1-\mathrm{E} \theta) d z^{\prime} ; \\
& d z^{\prime}=(1+\mathrm{E} \theta) d z, \text { approximately. }
\end{aligned}
$$

The volume of this layer on first solidifying was

$$
4 \pi z^{\prime 2} d z^{\prime} \text {. }
$$

And, after cooling, the thickness of this layer has contracted to $d z$, but has retained its horizontal extension. Its volume therefore becomes

$$
4 \pi z^{\prime 2} d z \text {. }
$$

Also, the proper volume of the spherical layer of the same thickness at this depth is

$$
4 \pi z^{2} d z \text {. }
$$

And the difference between these volumes will be the contribution to the surface-corrugations from this particular layer. Call the volume of the whole corrugations $4 \pi r^{2} h$; we then shall have

$$
4 \pi r^{2} \frac{d h}{d z} d z=4 \pi z^{\prime 2} d z-4 \pi z^{2} d z .
$$

But since every layer beneath the one in question has cooled

* Trans. Roy. Soc. Edin. vol. xxiii. pt. 1, p. 157. Also Nat. Phil. Appendix D; and Phil. Mag. 4th series, vol. Xxv. p. 1 (1863). 
Compression during Cooling of a Solid Earth.

through $\theta^{\circ}$, and contracted in the vertical dimension only,

$$
\begin{gathered}
\therefore z^{\prime}=\int^{z}(1+\mathrm{E} \theta) d z ; \\
=z+\mathrm{E} \int_{0}^{z} \theta d z, \\
\therefore r^{2} \frac{d h}{d z}=2 z \mathrm{E} \int_{0}^{z} \theta d z \text {, neglecting } \mathrm{E}^{2} .
\end{gathered}
$$

Dingram of temperature-curve, adapted from Sir W. Thomson's paper.

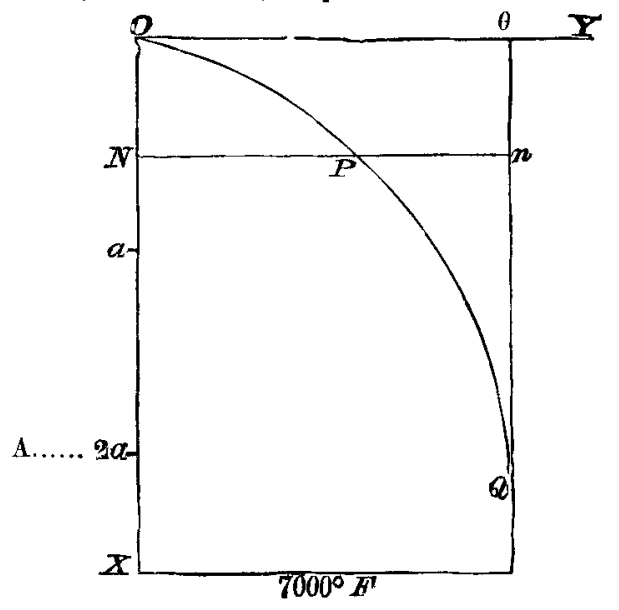

$0 \mathrm{~N}$ the depth below the surface $=x . \quad \mathrm{N} \mathbf{P}$ the excess of temperature above the temperature of the surface $=v$. OQ the excess of the melting temperature above that of the surface $=V . P n$ the temperature through which matter at the depth $x$ has cooled $=\theta . \quad$ O $a=a$.

Let $x$ be the depth of the layer under consideration from the surface at $O$. Then, using Sir W. Thomson's notation, we shall have

or

$$
\theta=\mathrm{V}-v \text {, }
$$

$$
\theta=\mathrm{V}-\frac{b}{a} \int_{0}^{x} \epsilon^{-\frac{x^{2}}{a^{2}}} d x
$$

$\mathrm{V}$ being the temperature of solidification, and $b=\frac{\mathrm{V}}{\frac{1}{2} \mathrm{~V} / \pi}$; and $a$ a depth, which may be determined at once (without knowing the conductivity or the time of cooling) by means of the formula $\frac{d v}{d x}=\frac{2 V}{a \sqrt{ } \pi} \epsilon^{-\frac{x^{2}}{a^{2}}}$, from the temperature-rate near the 
surface, which, taken at $1^{\circ} \mathrm{Fahr}$. per 51 feet, gives

$$
\frac{1}{51}=\frac{2 \mathrm{~V}}{a \sqrt{\pi}} \text {. }
$$

If we follow Thomson in assuming $7000^{\circ}$ Fahr. for the temperature of solidification (a very high value) this gives

$$
a=420832 \text { feet, }
$$

and at twice this depth, $\theta=\mathrm{V} \times 0.00468$; below which the cooling will be small. Let us then separate the integral into two portions at the point $\mathrm{A}$, at the depth $2 a$; and

$$
r^{2} \frac{d h}{d z}=2 z \mathrm{E}\left(\int_{\mathrm{CA}}^{z}+\int_{0}^{\mathrm{CA}}\right) \theta d z
$$

the second integral being the contribution to the surfacecorrugations from matter below $A$.

Setting this aside, since $z=r-x, \therefore d z=-d x$; and, supposing $\theta$ now expressed in terms of $x$ as above, reversing the order of the limits,

wherefore

$$
r^{2} \frac{d h}{d x}=-2(r-x) \mathrm{E} \int_{\alpha}^{2 a} \theta d x
$$

$$
h=-\frac{2 \mathrm{E}}{r} \int\left(1-\frac{x}{r}\right)\left(\int_{x}^{2 a} \theta d x\right) d x+\text { const. }
$$

The integral begins at $\mathrm{A}$, where $x=2 a$ and $h=0$;

$$
\therefore h=\frac{2 \mathrm{E}}{r} \int_{0}^{2 a}\left(1-\frac{x}{r}\right)\left(\int_{x}^{2 a} \theta d x\right) d x,
$$

gives the mean height of the corrugations formed out of the compression of the matter down to the depth $2 a$, which, with the assumed constants, will be about 160 miles.

If we substitute for $\theta$ the value given above, expand the exponential and integrate between the limits (see 'Physics' \&c. p. 63 et seq.), putting $\mathrm{E}=0.0000215^{*}, r=20902500$ feet, the above gives

$$
h=933 \text { feet. }
$$

The effect of the contraction below A need not be considered, being at most not two feet.

The value obtained for $h$ implies that, if all the elevations which would have been produced by compression, through the contraction of the earth cooling as a solid, were levelled

* This is the coefficient of contraction obtained from Mallet's experiments on slag. See 'Physics' \&c. p. 68. 
down, they would form a coating of about 900 feet in thickness above the datum level, which would be the surface, had the matter of the crust been perfectly compressible so that compression would not have corrugated it.

The value obtained for this quantity in my former work was $866^{\circ}$ feet.

Practically, these two numbers do not materially differ; and they show that, if we take into consideration the land and the ocean-basins, the existing inequalities of the surface are greater than can be accounted for by the theory of compression through contraction by cooling of a solid globe, even upon the too highly favourable suppositions made in the present paper. The strictly geological arguments against this theory stand upon their own merits.

The result of the above emendation of the demonstration in my 'Physics of the Earth's Crust' is therefore simply to confirm the arguments I have built upon the less satisfactory calculation given in chapter vi. of that book.

XIX. Silk v. Wire. By R. H. M. Bosanquet.

To the Editors of the Philosophical Magazine and Journal.

Gentlemen,

$\mathrm{N}$ a note in the December number of the Philosophical 1 Magazine for 1886, entitled "Silk $v$. Wire, or the 'Ghost' in the Galvanometer," I mentioned reasons for distrusting silk, and alluded amongst other things to the way in which it untwists when stretched. Condensation of expression has its inconveniences, and in the January number for $1887 \mathrm{Mr}$. Gray infers that I used a twisted silk thread, by which, I presume, be means an artificially-twisted silk thread; but that is not so. The thread used was prepared from suspensionsilk supplied by Elliott Brothers. This consists of a small number of fibres more or less aggregated to gether, and presents no appearance of twist. This is picked to pieces until the substance desired is left. It is then fine enough to be hardly visible.

I abandoned the use of cocoon-fibres and very small needles years ago in consequence of the impossibility of accurately determining the error introduced by the fibre.

I made at one time a great many observations on silk fibres of various descriptions. The phenomenon, to which I alluded in speaking of the untwisting when stretched, may be described as structural twist: it has shown itself as follows, in all silk fibres I have erer examined. 